\title{
Potential accessibility models and planning policy design in Romania: Are the fixed model's parameters leading to wrong interpretations?
}

\author{
Alexandru Rusu ${ }^{1 *}$, Octavian Groza ${ }^{2}$, Radu Necșuliu ${ }^{3}$ \\ 1 Alexandru Ioan Cuza University of Iași, Romania \\ 2 Alexandru Ioan Cuza University of Iași, Romania \\ 3 Ministry of Development, Public Works and Administration \\ * Corresponding author: alexrusucuguat@yahoo.com
}

Keywords: potential accessibility, distance decay, urban system, policy design

\begin{abstract}
This paper explores the differences between two different types of potential accessibility models applied to the urban system of Romania, using demographic data from 2015. The first model is based on a classical formalization of the potential accessibility function, while the second one focuses on the introduction of variable parameters in the model's equation. When mapping the results, one will found that the models we investigated respond to different needs and visions in spatial planning. The alternative formalization provides a frame for a more in-depth analysis of the transportation endowment, at regional scale, together with an assessment of the urban systems hierarchy. The study highlights the fragility of the local urban systems gravitating around small cities, placed in precarious accessibility situations. The results can be used for a better assessment of the policy priorities, both from the perspective of spatial planning and sustainable development.
\end{abstract}

\section{Introduction}

The history of the Romanian territorial planning policy, after 1989, can be easily split into 2 major periods of time. The first one is specifically anchored in the transition and EU pre-integration paradigms, when both policy makers and academic staff largely focused their studies on the territorial management of new and confusing trends, such as counter-urbanization, deindustrialization and rebuilding the spatial comparative advantages of economic branches or regions. It is the moment when "planning regions" and local interventions are defined and implemented (NUTS2 delineation, zone defavorizate (less favorable zones), industrial-parks or technological poles), their success varying as a function of economic extroversion, political lobby and local integration in the productive systems. The second period (after 2004) gradually shifts from this set of paradigms and incorporates a wider spectrum of planning and spatial analysis techniques, aiming to harmonize national practices with EU standards and expectations, in the field of territorial planning [1], [2]. The ESPON standards in research together with a deep infusion of quantitative methodology have a deep impact on the territorial planning design and on the sectorial master-plans and strategies in regional development, transportation or environment. This context of epistemological shifting is based on some recurrent concepts that, when mapped, legitimate the mentioned strategies and the master-plans of Ministries of Regional Development and Ministry of 
Transportation, in Romania. It is the case for spatial/territorial accessibility, connectivity, cohesion and competitiveness, geographical specificities or inner peripheries [3], [4].

The studies put an emphasis on the territorial accessibility concept, largely seen as an instrument for better coping with the national and regional needs, in the field of territorial endowment with transportation infrastructures. This aspect is particularly visible when this concept is mapped as a potential accessibility indicator. Following the French tradition of the spatial analysis, the potential accessibility indicator is sometimes labeled as modèle de potentiel d'interaction spatiale, with its rigorous translation into Romanian (model de potențial de interacțiune spatială). For example, the on-line version of the Atlas of Romania (2008),[5] which is a tool of territorial investigation commanded by the Ministry of Regional Development in Romania, uses it at least 8/10 times. The general frame of territorial planning for 2020 (The strategic concept of territorial development in Romania) also includes maps based on the potential accessibility concept, both from national and European sources (mainly ESPON). The first publication of this document was prepared as a general framework for national territorial planning. In a larger context, the concept is used for assessing the role of the highways in the territorial economic development in Poland or Spain [6], [7] or as scientific support for policy makers [8]. Territorial accessibility has become more and more important at both European and national level. Starting with the European Spatial Development Perspective [9], published in 1999, the need to improve accessibility of the whole territory has been highlighted in all the European strategic documents relevant for territorial development and cohesion (such as the initial Territorial Agenda and the subsequent revisions). In Romania, while the National Territorial Development Strategy has still not been approved by law, it has been endorsed as a governmental legislative initiative in 2016, confirmed in 2017. Getting more information on territorial accessibility and finding ways to improve it were key elements of the whole process which has been initiated back in 2008. The territorial dimension of the cohesion has been itself added only by the Lisbon Treaty (2006) and this has led to more focus on the territorial aspects, of which accessibility is highly relevant.

Accessibility needs to be a key element when designing the transport strategies, as well. One of the reasons for the lack of success of the Romanian transport policy has been the fact that for a long time the policy makers have focused too much on current vehicle traffic (documented in statements of persons in charge with the transport policy) and not on potential accessibility and the economic changes brought by a better transport network. Even now, the national transport model on which the Transport General Master Plan [10] is based on general indicators and does not take into account accessibility at local scale.

Potential accessibility should therefore be analyzed at different levels, to ensure coherence and complementarity between the national transport policy and the regional and local mobility interventions. Our intention is not to review the utility of this model, a utility that was already confirmed by numerous studies [11], [12], [13]. We rather intend to show that in specific territorial contexts like Romania, the use of the potential accessibility models should be revised, at least in relation with the model's parameters. More specifically, we develop an alternative theoretical method of calculation that 
provides results that describes better the Romanian territorial specificities. The main reason for the elaboration of an alternative version of the potential accessibility model is derived from the empirical lack of calibration, regarding the parameters used in the formalization. Romania and Poland are among the few EU states that still ignore the publication of a sound spatial interaction matrix between their national LAU2 - Local Administrative Unit (flow matrices). This aspect negatively interferes with the empirical validation of gravity deduced models (potential accessibility, polarization, dominant flows mapping etc.), with a clear impact on the territorial policy design. Despite this lack of information, intermediate formalizations of the potential accessibility, placed between pure theoretical models and empirically validated ones, are a distinct possibility. This paper presents the implementation steps of one specific model, compared to theoretical-canonical ones.

\section{Theoretical background}

The early '50 and the late ' 60 period is marked by an intense transformation of the geographical disciplines, transformations characterized by an intense use of quantitative tools and neo-positivism approaches. One distinct direction of study, during the emergence of this paradigm, addresses the spatial formalization of regional markets, in an attempt to geographically review and rewrite some of the classic micro-economic models. The initial research focuses on mathematical models describing the location of the territorial offer of services, based on the inter-war attempts of Reilly [14], [15]. The results are rapidly transferred from the field of economic geography to other disciplines, such as urban geography and regional planning, together with an intense trend of sophistication and problem-solving orientation [16]. The first uses of the potential accessibility models are linked with these attempts of pre-quantitative geographers to model the role played by the demand in the construction of the economic markets, from a spatial perspective [17], [18]. In its basic formalization, Stewart is modeling the demand using an inverse distance function. Later, Taylor [19] enlarges the different conceptualizations of the role played by distance in the elaboration of the accessibility models, and a large amount of geographers find consensus in the mobilization of exponentially based functions in their work. Due to their versatility, the potential accessibility functions are rapidly integrated in planning studies, being used as territorial impact assessment tools [20], [21], as prospective indicators [22], [23], or proxy for different analytical approaches of territories, at European [24], [25]. In the late '80s and early '90s, the French school of quantitative geography developed its own theoretical approach of the potential accessibility model, in an attempt to bridge its formalization with classical gravity models [26], [27]. The path of the French school was also followed in the Romanian geography, the methodological import of techniques and instruments covering a large area of applied studies and policy design support documentation [28], [29], [30]. From the EU policy makers and stakeholders' perspective, some of the ESPON 
PESD 2021, 15, 1

(European Spatial Planning Observation Network) studies deeply rely on the conceptualization of potential accessibility, such as, TRACC, PROPHECY, Europe in the World or ESPON DB projects. Other EU Directories (DG Move) investigate or use potential accessibility functions for specific models, like the TRANS TOOLS 3 Project, developed by the Joint Research Centre's Institute for Prospective Technological Studies.

\section{Methodology}

The class of potential accessibility models includes a large area of formalizations, mainly due to the diversity of the distance decay functions that researchers will use for mapping purposes. One of the most widely spread and intensely used (abused?) in the Romanian academic and planning policy design is the pseudo-Gaussian negative exponential function. The model of this function is based on a set of assumptions that makes it suitable for the analysis of the urban systems interactions and for the assessment of transportation network efficiency. The first assumption is that the spatial interactions (the potential flows) will decay with distance between origins and destinations, a decay that is similar to a Gaussian distribution [31]. The control point of the function is provided by two coordinates: the level of potential interaction expressed on $Y$ axis and the distance where the potential interaction takes the value of $0.5(50 \%)$. The second assumption fixes the role played by the general territorial accessibility in the declination of flows between the spatial units. It is controlled in the function by a distance parameter generally equal with 2 .

Using these 2 assumptions, the formalization becomes:

$$
P A_{i}=\sum_{i}^{j}\left(e^{\alpha * D i j^{\beta}} * Q_{j}\right)
$$

where,

$P A_{i}=$ the potential accessibility function for any point $i$ in the study area

$e=$ the exponential constant

$\alpha=\ln (0.5) / H F^{2}$ and HF means the distance from $i$, where the potential interaction is equal to 0.5 [32]. However, it is not compulsory to use 0.5 as control point on $Y$ axis, one can use 0.66 or 0.25 , depending on the study hypothesis. The French school of spatial analysis prefers the term of portance spatiale instead of "half-life".

$D i j=$ is the distance between any two points $i$ and $j$ in the study area. It can be Euclidian distance, Manhattan distance, kilometers, time or cost distance. The choice is operated by assessing the transportation networks of the studied region.

$\beta=$ the distance parameter that controls how permissive is the regional space for interactions 
$Q_{j}=$ the mass of any point $j$ in the study area. For example, if potential accessibility studies are implemented at the EU scale, indicators such as regional or local GDP can be integrated in the model.



Figure 1 Simulation of potential accessibility functions using a $\mathrm{HF}=25$ and a $\beta=2(\mathrm{f} 1)$, $\mathrm{HF}=75$ and $\mathrm{a} \beta=2$ (f2), $\mathrm{HF}=25$ and $\beta=1.5$ (f3)

The function relies on two parameters $-\alpha$ and $\beta$, the first one being responsible for the control of the distance decay, the second one for the shape of the mathematical function on the plot. From this point, simulations can be made on the parameters, in order to observe what impact they might have on the shape of the function. The choice of the values for $\alpha$ and $\beta$ is usually dictated by a bibliographic review or by the surface of the study area [33], [34]. The simulation shows that the parameter $\beta$ plays an important role in the model's elaboration. Values of $\beta$ close to 1 increase the potential accessibility, while values in the proximity of 2 will have a negative impact on the indicator.

Based on the implementation of a non-linear regression, the values of the parameter $a$ could be empirically estimated using a spatial interaction matrix and cumulative flows sums as distance functions. Theoretically, the quality of the adjustment will not be similar for spatial interactions describing commuting processes or for interactions in the urban services catchment areas. However, when basic data on flows is missing, like in the case of Romania or Poland, estimations can be made so that the values of $a$ are not a constant in the model, but varying either continuously or discretely. For our methodological investigation, we have made an option to implement a discrete evaluation of the $a$ parameter, using the population of the Romanian cities in 2015 as a proxy indicator. As in many other cases, the demographic categories can be refined or readjusted, based on the territorial frame of reference, our classification serves just for research purposes. 
Table 1 Categories of Romanian cities by population and expert-opinion assigned values for HF parameter

\begin{tabular}{cccc}
\hline Min. pop. (cities) & Max. pop. (cities) & HF (min.) & Count \\
\hline 2103346 & 2103346 & 240 & 1 \\
291195 & 357192 & 120 & 7 \\
136710 & 234969 & 90 & 10 \\
85029 & 123378 & 60 & 14 \\
52507 & 77997 & 45 & 14 \\
29264 & 47969 & 30 & 33 \\
9809 & 28542 & 20 & 127 \\
1674 & 9716 & 10 & 114 \\
\hline
\end{tabular}

The logic of the a parameter categories lays on the urban hierarchy in 2015. For instance, Bucharest and large cities like Cluj-Napoca, Iași or Timișoara will have larger values for the HF (240 minutes and 120, respectively). Regional cities like Ploiești or Brăila will receive a lower value of 90 minutes. Intermediate and medium cities are assigned with values ranging from 60 to 30 minutes. Finally, the small cities will present a HF of 20 or 10 minutes, according to their population. The values of the HP for each category are based on the interpretation of several sources of indirect flows data. For the large and intermediate cities with tertiary educational infrastructures, we used approximations of their students' catchment areas. For medium and small cities, the approximations were derived from the inter-city time tables of public transportation in 2019.

Even in the case where a flows matrix would be available, precaution is needed when estimating the value of the a parameter, via the HP. Bucharest and the large Romanian cities are in the core of metropolitan areas, involving a large amount of proximity flows. When these networks of metropolitan proximity are accounted, they will limit the extent of the HP value.

Compared with the values of the $a$ parameter, the $\beta$ is much easier to estimate, once a general accessibility index is built, for the studied territory (Romania, in our case). Mathematically, we associate low values of accessibility with $\beta=2$ and high values of accessibility with $\beta=1.5$ Intermediate accessibilities range between 1.5 and 2 , using a continuous linear function for this purpose.

In our alternative model, we propose a function of the potential accessibility to urban population in Romania that takes into account parameters with variable values. Once the model is built, it will be confronted with a function that is formalized in a canonical way ( $a$ and $\beta$ are fixed values). The differences between the two models will be analyzed and interpreted in the context of policy design utility. From a critical point of view, the methodology we propose does not deal with two major issues of the potential accessibility model, issues that are independent to both the models we implemented baseline and alternative. The first problem is related to the potential flow emissivity of the destinations $j$ dataset. Given the models formalization, in some cases, researchers might face the possibility that a polarized spatial unit $j$ will emit flows larger than its own mass 
Q. Correcting this issue involves the introduction of supplementary constraints in the model, in order to cut-off excedentary spatial interactions. The second problem is related to the model design, more precisely to the nature of the distance decay functions chosen for modeling [35]. Both in the baseline and the alternative form, we assume that there is only one distance decay function describing the potential accessibility. However, there is no logical objection to use different functions in order to describe the same set of spatial interactions. As a matter of fact, some cities might be subject to a specific form of distance decay potential accessibility (e.g. exponential), while other cities might follow a very different pattern [36]. From a methodological perspective, in the case of Romania, the questions are opened as far as no empirical flows based evidence might be provided [37].



Figure 2 Algorithm for an alternative model of potential accessibility to the urban population in Romania (2015)

\section{Model's implementation}

The algorithm we propose is based on a number of steps that involves the use of specific GIS tools and tabular calculation. The implementation of tools and the geo-statistical approach of the input data demand a set of basemaps that includes:

- a road network dataset for the evaluation of the time distances between the cities. There are 2 options for this dataset. The first one is provided by the Eurogeographics Open Data national geo-databases. The second option would be the use of OSM road network layer. Despite the fact that the number of road segments is lower in the first case, we made an option for Eurogeographics Open Data. There are several reasons for that, but the most important is related to the connectivity properties of the network we 
choose. The roads segments are qualitatively classified, which allowed us to calculate time-distances in the model. In this case, the highway segments received an average speed of transportation of $90 \mathrm{~km} / \mathrm{h}$, the national roads $-60 \mathrm{~km} / \mathrm{h}$, the county roads -45 $\mathrm{km} / \mathrm{h}$ and the local roads $25 \mathrm{~km} / \mathrm{h}$. These speeds are consistent with the last two traffic census from 2011 and 2015, no other speed references being available for our estimation.

- the second layer needed for the elaboration of an alternative potential accessibility model is the LAU2 delineation provided by the ANCPI (National Agency for Cadaster). The dataset is available in multiple versions, but our analysis uses the version provided by geo-spatial.org, a curated and updated layer ready to be integrated in GIS analysis. From this layer, we extracted the categories describing the cities, according to the national rank. For example, rank 0 is reserved for the capital (Bucharest), the rank 1 labels concerns the large cities with complex functions, rank 2 is allocated to cities with important regional functions and rank 3 for cities with local relevance only. This classification also appears in the PATN (National Spatial Plan) in the early 2000 and it was not revised since then [38]. Each city we extracted was located in the road network by specific GIS operations (ArcMap Network Analyst - Calculate locations).

- once the network dataset was created and the city layer obtained, a time distance matrix between the cities was realized, using the ODC matrix from the same extension (Network analyst) of ArcMap [39]. Recurrent joins with the city database file were also needed, in order to enrich the time distance matrix with new indicators: population at origin and destination ( $i$ and $j$ ) and NUTS2 belonging of cities ( $i$ and $j$ ). New fields were also reserved for the implementation of the baseline model (fixed values of the parameters) and for the alternative one (potential accessibility model with variable parameters).

The indicator time distance (Total_TMP) in the model reflects the time distance between any two pairs of Romanian cities $i$ and $j$, expressed in minutes. An average value of this indicator can be calculated for any $i$ city, providing the accessibility index for the urban system [40], [41]. The formalization of this general accessibility model is:

$$
A i=\frac{\sum_{i}^{j} D i j}{n}, \text { where: }
$$

$A i=$ time accessibility of a city $i$ expressed as the average of the time distances that separates it from other urban entities

$n=$ number of cities included in the study (325 urban LAU2, including Bucharest sectors)

Based on the values of the general accessibility model, an index of accessibility can be calculated as follows:

$$
A I i=\left(2-\frac{\sum_{i}^{j} D i j / n}{\min \left(\sum_{i}^{j} D i j / n\right)}\right) * 100
$$

In the frame of our research, we use a symmetric matrix of origins and destinations between cities. For other planning studies, indicators derived from asymmetric tables can 
be used (e.g. distances to airports, universities or other public services of general interest). High values of this index indicate good accessibility in the road system (when time distances are taken into account), while the low values point the opposite. The accessibility index can be mapped using an inverse distance interpolation (IDW), for a continuous result or surface. The coefficients of the IDW model are:

Distance power function: 3.86

Quality of the adjustment between measured and predicted values: $0.95 *$ Measured values +3.05

RMSE (root mean square errors) $=2.6$;

The errors of the interpolation are independent in relation to the measured values. From a geo-statistical point of view, these parameters describe well the quality of the cross-validation between the interpolated and the measured values. Better results might be obtained, if the IDW method will be constrained to integrate variable coefficients [42]. However, this methodological adjustment is not feasible under a common GIS platform like ArcGIS or QGIS.

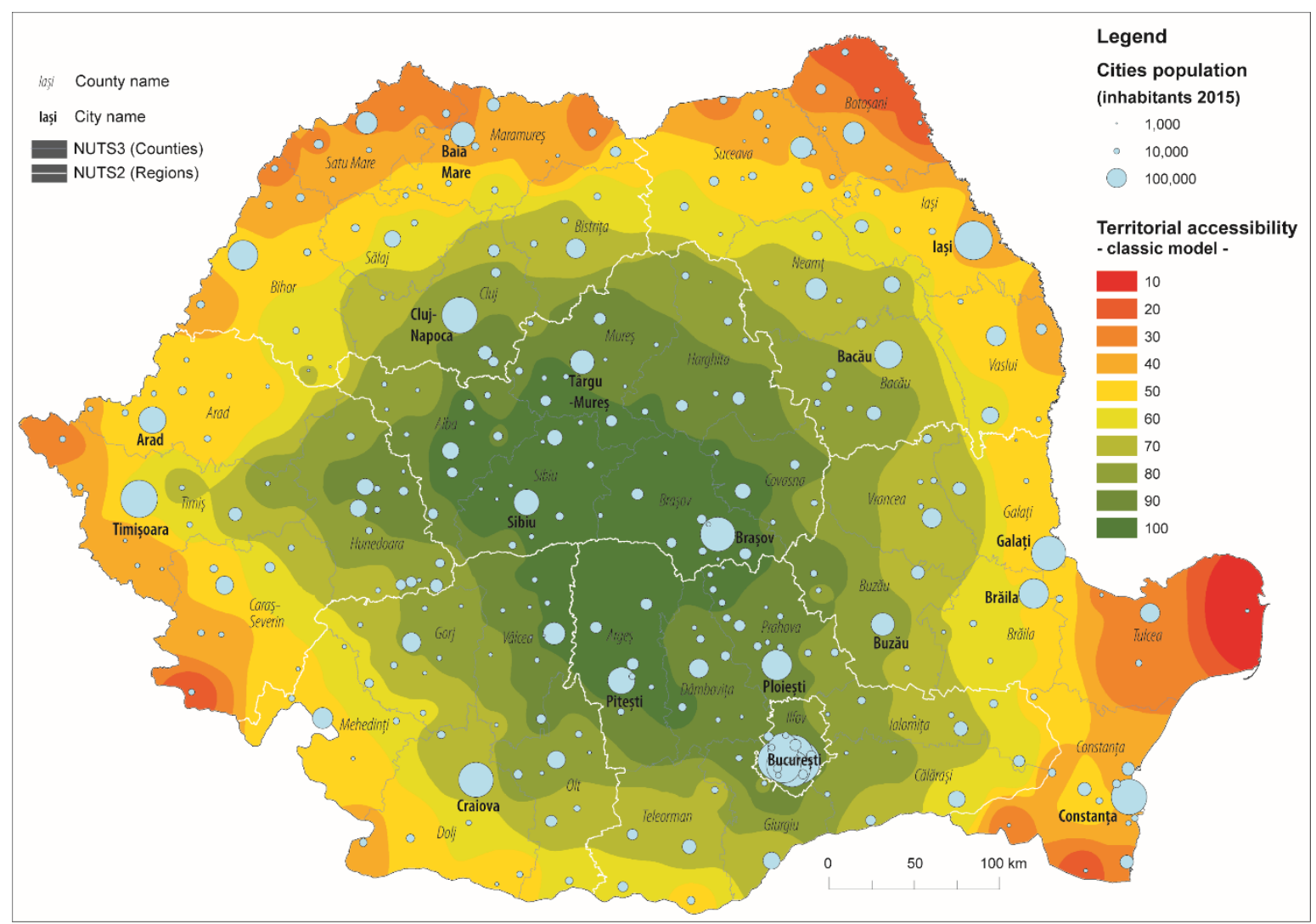

Figure 3 The general accessibility map of the Romanian cities based on a time distance matrix (road network)

The Figure 3 depicts a classical center-periphery organization model of the road accessibility measured as time-distance. The central triangle of maximum accessibility has edges in three large or intermediate Romanian cities - Brașov, Sibiu and Pitești. Areas with good or fair accessibility elongate towards Bucharest or Deva (to the west), after that the values of index gradually decrease towards the peripheral regions. The case 
of South-East region is interesting. Despite the fact that this region has a superior territorial endowment ( $\mathrm{A} 3$ highway in the county of Constanța), the general accessibility is rather poor, due to its weak road network connectivity and the presence of the Danube River which acts as a road barrier. Moreover, the presence of the Danube Delta in this

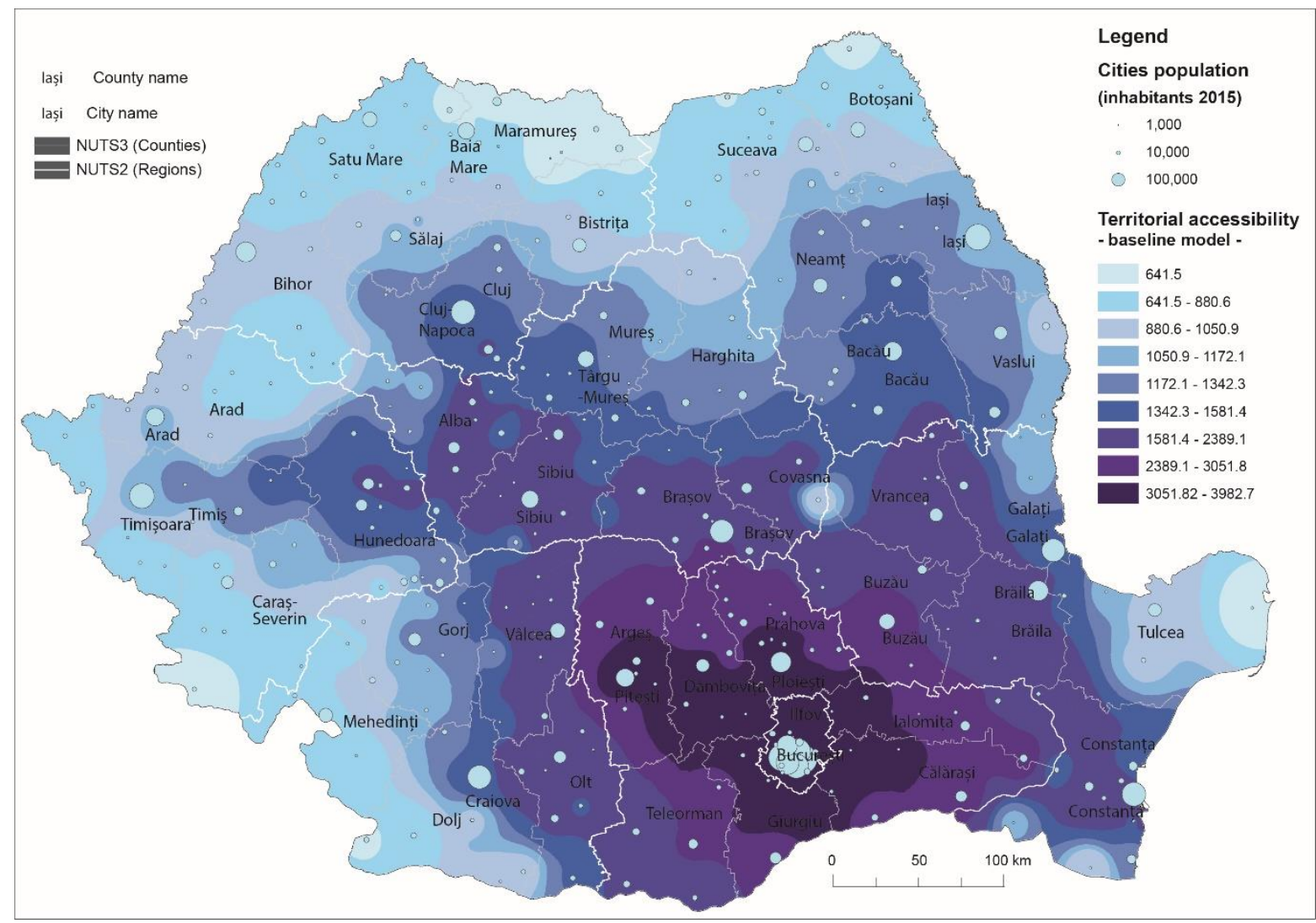

Figure 4 Potential accessibility to urban population in Romania in 2015 - alternative model

region complicates even more the local network connectivity, inducing no terrestrial road connectivity for the town of Sulina. In the North-East region of Romania, one county is severely affected by a lack of general accessibility in the road network - the county of Botoșani, with three of the lowest accessibility classes present on its territory. The spatial distribution of the accessibility index emphasizes the role played by the distance in the potential accessibility model. This suggests that in contexts of fair territorial accessibility, the distance is more permissive in the development of the spatial interactions. In remote regions, where the AIi index has low values, the spatial interactions will be proportionally decayed. In our formalization, the distance's role is played by the $\beta$ parameter, a parameter that we vary as a linear function of the general accessibility index AIi (between 1.5 and 2). In the same time, the 50\% theoretical catchment area of each city $i$ in the database was weighted as a function of city's demographic importance (from 240 minutes to 20 minutes, for the HP parameter). The implementation of the model provides interesting results (Figure 4), sometimes in a total dissonance with the canonical maps of potential accessibility generally used by policy designers and decision takers.

Mapping the results of this alternative formalization with variable parameters $a$ and $\beta$ (Figure 4) shows an uneven distribution of the potential accessibility, in the Romanian 
territory. The role played by the general accessibility in the road network is highly important in explaining why cities with a lower demographic importance benefit from superior potential accessibility to the urban population. It is the case for Sibiu, Pitești, Brașov and Târgu Mureș. As a general rule, cities closer to the core area of high general accessibility are also promoted in the hierarchy of the potential accessibility. In the peripheral regions, cities like Iași, Constanța or Timișoara, despite being in the first ranks of the urban system, are penalized by their remoteness to the central regions delineated by the urban "quadrumvirate" of Sibiu-Brașov-Pitești and Târgu Mureș.

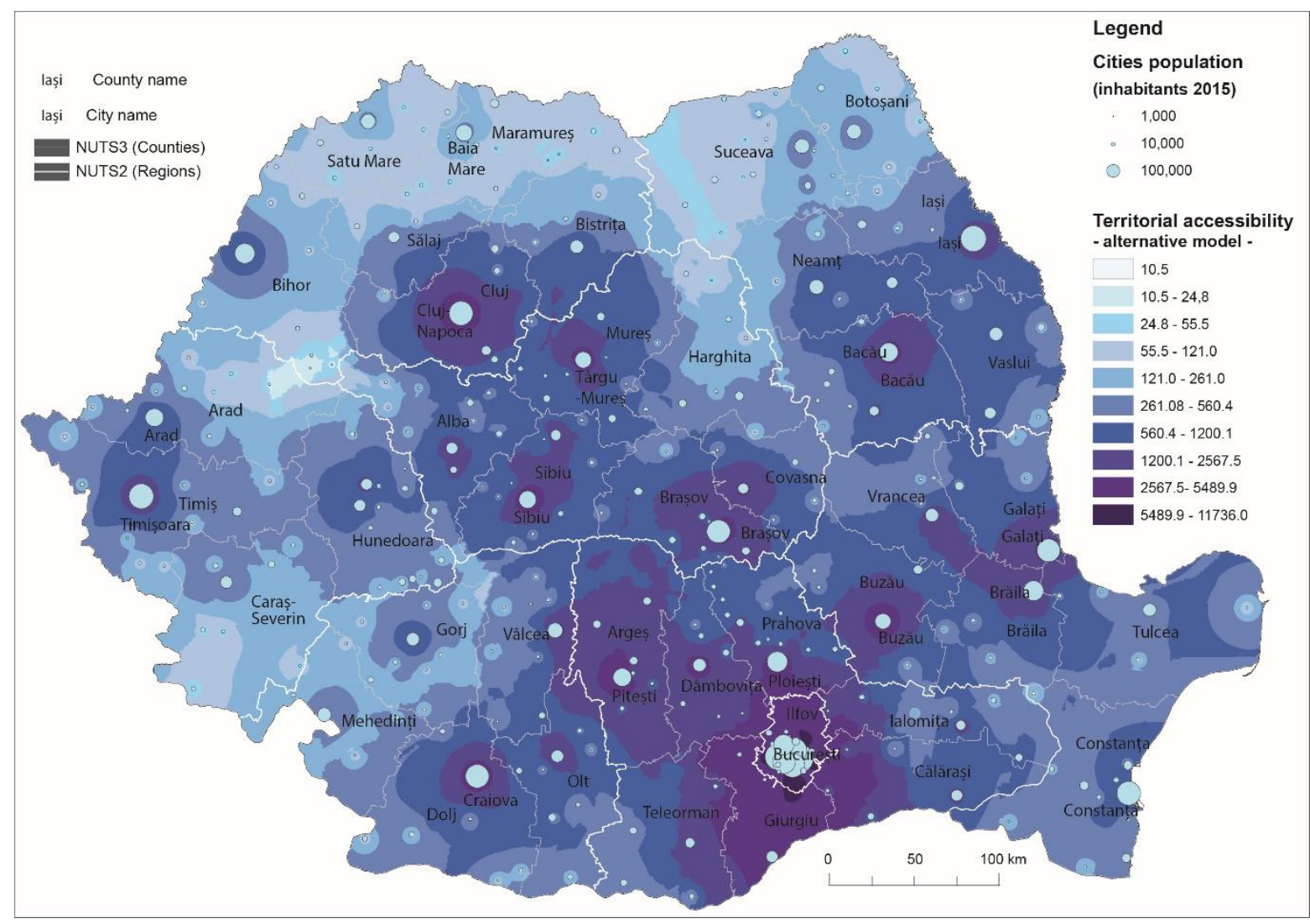

Figure 5 Potential accessibility to urban population in Romania in 2015 - baseline model

The baseline model serves as a frame of results comparison and it uses fixed parameters ( $a$ uses a HP of 120 minutes and $\beta$ is 2) for the delineation of the potential accessibility to urban population. Taking into account the primacy of Bucharest in the urban system (2 103336 inhabitants 2015, compared with the $2^{\text {nd }}$ rank city of Iași - 357 192 , according to the population with official residence of 2015 recorded by NSI) and the fact that 3 major Romanian highways are convergent towards the capital, the canonical model will mathematically emphasize this region as being the major pole of potential accessibility to the urban population. At regional scale, no major Romanian city ( $>300$ 000 inhab.) is placed in a fair position, not even the conurbation of Galați-Brăila, even if it cumulates 518791 inhabitants. The gradients of the baseline model of potential accessibility decrease towards the peripheral regions with different rhythms that are weighted by the territorial endowment with quality road network segments (mainly highways and 2 lanes express roads like some of the E corridors). 
In the peripheral regions of Romania, the potential accessibility described by the baseline model is limited by the distance to the major axis of transportation, but also by a less dense urban network [43]. This combination of factors is visible in the southern areas of the West NUTS2 Region, in the western part of the South-West NUTS2 Region or in the North of the country. Also, these "angles-morts" of the baseline model of potential accessibility have few options of trans-national urban interactions, being placed in territorial contexts with limited opportunities - frontiers with Ukraine, Serbia or Bulgaria [44]. This situation is explained by the presence of the external border of the EU, in the case of Ukraine and Serbia, or by natural barriers and insufficient economic cooperation, like in the case of Bulgaria.

For policy design, choosing one model or another is not indifferent, as the planning intentions can be severely altered by the maps and geo-statistical results interpretation. Despite its lower values of stock potential accessibility, the alternative model underlines the role played by the superior part of the urban hierarchy in the spatial distribution of the indicator. It is a model suitable for a policy design associated with a territorial cohesion vision of planning. The baseline model emphasizes the role of Bucharest and its convergent superior road network and seems optimal for decisions based on territorial competitiveness agenda.

\section{Discussion}

The output of the models implemented in the results section can be compared and discussed in terms of policy design relevance for territorial planning. The first indicator derived from the models construction is the share of intra-regional potential accessibility. It measures how much of the total amount of urban population available in a Gaussian exponential-negative spatial kernel is available due to the internal regional endowment with an urban network. In the baseline model, the values of this indicator create a set of spatial structures that might be useful, from a policy maker perspective. The belts of high share of intra-regional potential accessibility ( $>75 \%$ ) are located in the peripheral areas of Romania, but with some strong regional differences. For example, in the South-East NUTS2 region, this belt covers areas with limited road connectivity, such as the Danube Delta and the northern part of the Tulcea NUTS3. In the South-West NUTS2 Region, this belt is confined in a remote area of the Dolj NUTS3 - the minor cities of Băilești and Calafat. As the time-distance to Bucharest increases, the area occupied by these belts also increases. In the West NUTS2 region, this growth is moderate, but it includes one of the large cities of Romania - Timișoara (333 613 inhab. in 2015). In the North-West, the isoline of more than $75 \%$ internal regional potential accessibility overlays almost half of the NUTS2 surface, including cities placed in medium to high positions in the urban hierarchy - Satu Mare or Baia Mare. The critical situation appears in the North-East NUTS2 Region, where almost two thirds of its surface is occupied by this isoline, covering four cities with national or regional relevance - Iași, Botoșani, Suceava and Piatra Neamț. The second belt analyzed is the isoline of more than $50 \%$ share of intra-regional potential accessibility, in the baseline model. Its trajectory on the map is partially associated with areas of superior general accessibility, in the Romanian territory, excepting the appendix 
towards east, in the central part of Transylvania. Many cities with national or regional relevance are situated in this belt: Craiova, Cluj-Napoca, Galați, Arad, Oradea, Târgu-Mureș, Bacău and Brăila. For this set of urban geographical entities, the spatial interactions realized within their own NUTS2 spatial frame are still overcoming their potential for regional extroversion. Flanking the capital region in the east, north-west and south-west, the belt of $25 \%$ intra-NUTS2 potential accessibility includes cities with a low relevance for the national or regional hierarchy, except for Buzău and Pitești. Even in their case, the proximity of Bucharest dictates the high amount of potential spatial interactions, in an inter-regional context, making difficult to really estimate how extrovert these two cities really are. As the general organization of the gradient share of intra-regional accessibility potential to urban population is shaped by the isochrones to Bucharest, interpreting the results of the baseline model is rather useful for a policy design aiming to increase the territorial competitiveness, exploiting the regional ratios of extroversion. For policies oriented to the management of the territorial cohesion, decision takers might prefer the results obtained by the implementation of the alternative model.

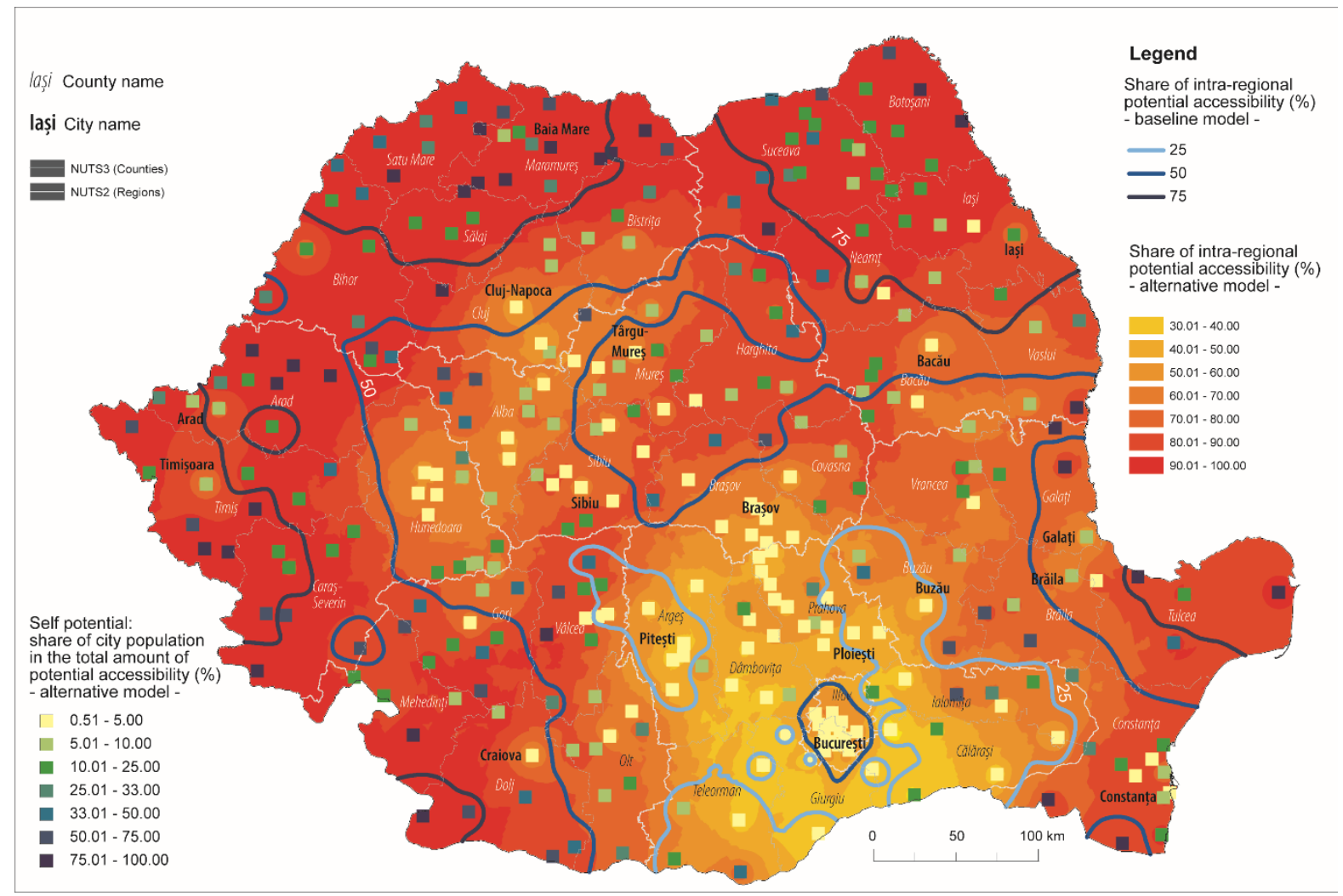

Figure 6 Baseline vs. alternative model - a comparison of various cartographic outputs

The use of variable parameters in the alternative model creates a potential accessibility indicator that points out indirectly the deficiencies in regional endowment with efficient road transportation networks, together with some of the demographic gaps in the regional urban systems. As a general rule, from the perspective of the indicator we derived - share of intra-regional potential accessibility, the alternative model shows that this ratio is spatially adjusted by the distance to the capital region, in a national core-periphery model. This result is the output of a systemic problem of the Romanian 
urban system, as the regional distribution of cities is far from being uniform. The gradient type concentration of urban entities in the North-East, North-West or West Development Region partially explains why the values of the intra-regional potential accessibility are so high in these areas. Moreover, a large amount of these cities has a small demographic size and, according to the model we implemented, is unlikely for them to insert in long distance interactions with other cities. The values of the indicator describing the set of small urban entities are strongly related to their own self-potential, as Figure 7 emphasizes.

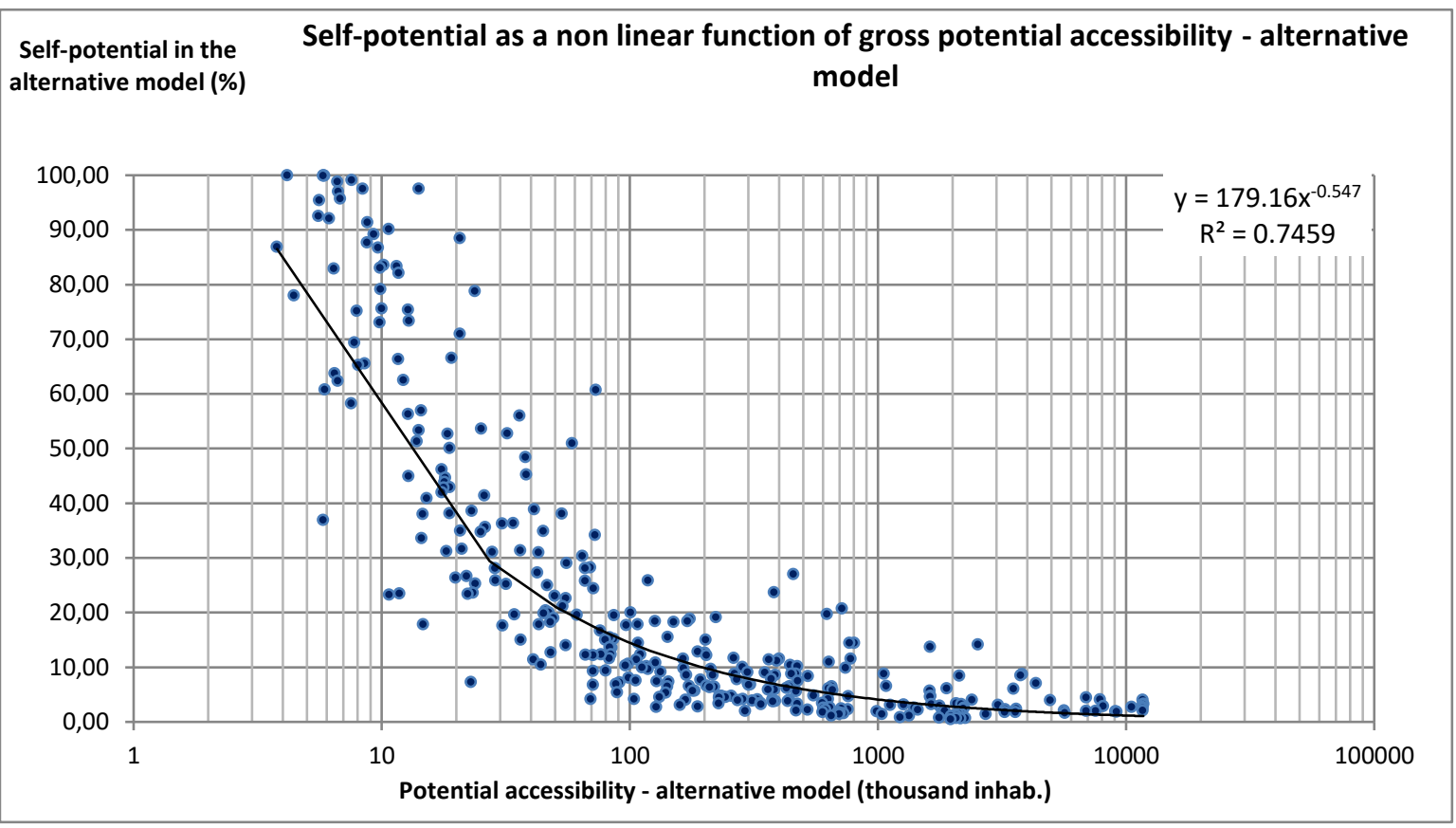

Figure 7 Statistical investigation of the self-potential share in the alternative model.

The basic interpretation will suggest that the potential accessibility of cities dictates the share of the self-potential values in the construction of the indicator, following a negative power function with an exponent of -0.547 . Some of these small cities are not able to properly interact with other urban entities, according to the constraints imposed by the alternative model. It is the case for some remote towns like Băneasa and Negru Vodă (Constanța county), Sulina (Tulcea county), Târgu Bujor (Galați county) and Ștefănești (Botoșani county), where the value of the self-potential contribution is more than $99 \%$. The city of Băneasa was declassified as urban entity in 2019, after a local referendum. It is an interesting case that illustrates how the alternative model and the self-potential might function as filters for urban viability, in the case of small towns. It also brings into discussion some technical aspects related to the implementation of policies in fields related to spatial planning, such as the sustainable development at different scales, mainly local and regional. As the urban entities are key elements in achieving policy objectives of sustainable development, the fragility of the small cities, as emphasized in the case of the potential accessibility model and maps, partially undermines these strategies. In this case, a mix of policy approaches from different fields of action (urban studies, transportation, environment and green economy etc.). 
The analysis of the self-potential share indicates that, without access to empirical spatial interactions for validation, the alternative model might face some severe design problems related to the coefficients describing the role played by small cities in the urban systems [45]. A possible solution will be to apply the model only for a selected set of urban entities (e.g. cities with a population larger than 25000 inhabitants). Further explorations of this method might also include rural LAU2 with some incipient rural functions, in order to detect potential candidates for urbanization.

\section{Conclusions}

From a theoretical perspective, one can speculate that the quantitative models in geography and planning studies might be linked to their potential of speciation, meaning their ability to present constant upgrades, as a function of new needs. It is the case for the classical models of spatial interaction, such as the gravity model, but also for the model of potential accessibility. Our methodological investigation points out that the adjustment of the canonical parameters in the formalization enables new territorial visualizations of the interactions within the Romanian urban system. These new visualizations might push forward research directions in both planning and sustainable development areas of interest. The outputs of the alternative model can be used for a better understanding of the role played by the Romanian major cities in their regional context, contributing thus to a better articulation between different levels of planning interventions, in the case of transportation and territorial endowment. The assessment of differences between the baseline and the alternative model is interesting from the intra-regional distribution of urban potential accessibility. The shape and the orientation of the gradients describing this indicator are rather stationary, from a spatial point of view, the differences being induced by their intensities. Therefore, the model of potential accessibility with varying parameters can be used as a tool for the detection of inter and intra-regional territorial homogeneity of the urban interactions. One final output of the modeling consists in the interpretation of the endogenous urban contribution to the model, via the values of the self-potential. The geo-statistical interpretation of the results shows that small cities in peripheral accessibility contexts are more likely to develop weak urban interactions, an aspect that becomes an interesting topic for planning analysis and action. With static models and constant variables, the maps and the outputs of the modeling processes always lead to partial conclusions, as they exclude the dynamics of the territorial systems. Flexible parameters in the formalization enable the elaboration of regionally tailored measures of planning interventions, definitely more suitable for complex urban systems, like the Romanian one. Finally, an alternative model of potential accessibility using variable parameters opens new interrogations regarding the empirical validation of the formalization. Our approach indicates that the utilization of discrete cut-offs for the distance decay function provides a good base for further simulations. In order to pass from simulation to planning scenarios, the only alternative is to access the Holy Grail of the Romanian quantitative geography, which is a sound database of spatial interactions. 


\section{References}

[1] Conceptul strategic de dezvoltare teritorială - România 2030, MDLPL - INCD Urban Proiect, 2008

[2] STRATEGIA DE DEZVOLTARE TERITORIALĂ A ROMÂNIEI - România policentrică 2035, Coeziune şi competitivitate teritorială, dezvoltare şi şanse egale pentru oameni, MDRAP, 2015

[3] PROFECY - Inner Peripheries: National territories facing challenges of access to basic services of general interest, ESPON, 2017, https://www.espon.eu/inner-peripheries

[4] Scenarios for accessibility by the sea, road, rail, air and multimodal, ESPON, 2020, https://www.espon.eu/access-scenarios

[5] Atlasul teritorial al României - instrument de analiză teritorială, CUGUAT-TIGRIS, MDLPL, 2008, http://old.mdrap.ro/ documente/atlas/index.htm.

[6] Piotr Rosik, Marcin Stępniak, Tomasz Komornicki, The decade of the big push to roads in Poland: Impact on improvement in accessibility and territorial cohesion from a policy perspective, Transport Policy, Volume 37, 2015, Pages 134-146, ISSN 0967-070X, https://doi.org/10.1016/j.tranpol.2014.10.007.

[7] Gutiérrez, J., Location, economic potential and daily accessibility: an analysis of accessibility impact of the high-speed line Madrid-Barcelona-French border. Journal of Transportation Geography, 2001. , 9 (4), https://doi.org/10.1016/s0966-6923(01)00017-5.

[8] Schürmann, C., Spiekermann, K., Wegener, M. Accessibility indicators: model and report. In: SASI Deliverable D5. Report to the European Commission. Institute für Raumplanung, Universität Dortmund, Dortmund, 1997.

[9] ESDP European Spatial Development Perspective Towards Balanced and Sustainable Development of the Territory of the European Union, Agreed at the Informal Council of Ministers responsible for Spatial Planning in Potsdam, May 1999, Published by the European Commission, https://ec.europa.eu/regional policy/sources/docoffic/official/reports/pdf/sum en.pdf

[10] Variantă finală revizuită a Raportului privind Master Planul pe termen scurt, mediu și lung, Guvernul României, Ministerul Transporturilor, 2016

[11] Gutiérrez, J., Condeço-Melhorado, A., López, E., Monzón, A. Evaluating the European added value of TEN-T projects: a methodological proposal based on spatial spillovers, accessibility and GIS. Journal of Transportation Geography, 19, 2011 https://doi.org/10. 1016/j.jtrangeo.2010.10.011

[12] Holl, A., Twenty years of accessibility improvements. The case of the Spanish motorway building programme. Journal of Transportation Geography, 2007, 15 https://doi.org/10. 1016/j.jtrangeo.2006.09.003.

[13] Biosca, O., Spiekermann, K., Stępniak, M., Transport accessibility at regional scale. EUROPA XXI, 2013, 24, 15-17. https://doi.org/10.7163/Eu21.2013.24.1.

[14] Reilly, W. J. The law of retail gravitation. Knickerbocker Press: New York, USA, 1931

[15] Batty, M. Reilly's challenge: new laws of retail gravitation which define systems of central places. Environment and Planning A 1978, 10, pp. 185-219

[16] Huff, D. L. Defining and Estimating a Trade Area. Journal of Marketing, 1964, 28, pp. 34-38

[17] Stewart JQ: An Inverse Distance Variation For Certain Social Influences. Science. 1941, 93: 89-90. 10.1126/science.93.2404.89.

[18] Stewart, J.Q. Empirical Mathematical Rules concerning the Distribution and Equilibrium of Population, Geographical Review, 1947, 37 (2), 461-485, https://doi.org/10.2307/211132

[19] Taylor P, Distance decay in spatial interactions. Concepts and Techniques in Modern Geography. 1975, No2

[20] Stępniak, M., Rosik, P., From improvement in accessibility to the impact on territorial cohesion: the spatial approach. Journal of Transportation and Land Use, 2016, 9 (3), 1-13. https://doi.org/10.5198/jtlu.2015.570

[21] López, E., Gutiérrez, J., Gómez, G., Measuring regional cohesion effects of large- scale transport infrastructure investments: an accessibility approach. European Plannning Studies, 2008, 16, 277-301, https://doi.org/10.1080/09654310701814629 
[22] Schürmann, C., Talaat, A., Towards a European Peripherality Index. Final Report. vol. 53 Report for General Directorate XVI Regional Policy of the European Commission. Berichte aus dem Institut für Raumplanung der Universität Dortmund, 2000

[23] Spiekermann, K., Neubauer, J., European Accessibility and Peripherality: Concepts, Models and Indicators. Nordregio Working Paper, 2002, Stockholm

[24] Grasland, C.-Mathian, H.-Vincent, J Multiscalar analysis and map generalisation of discrete social phenomena: Statistical problems and political consequences. Statistical Journal of the United Nations Economic Commission for Europe, 2000, 17 (2): 157-188

[25] Keeble, D., Owens, P.L., Thompson, C., Regional accessibility and economic potential in the European community. Regional Studies, 1982, 16, 419-432

[26] C. Grasland, Seven proposals for the construction of geographical position indexes, Study Program on European Spatial Planning, Working Paper from SDEC-France, 1999

[27] Boursier-Mougenot, Isidore, Nadine Cattan, Claude Grasland, and Céline Rozenblat. "Images De Potentiels De Population En Europe." L'Espace Géographique, 1993, 22, no. 4, 333-45 http://www.jstor.org/stable/44381243.

[28] Atlasul României, Rey V., Groza O., Ianoș I., Pătroescu M., RAO, 2006

[29] Groza, Octavian, Polarizare urbană şi cadru administrativ în România. The missing link, in Lucrările Seminarului « Dimitrie Cantemir », 2001, no 21-22, Departamentul de Geografie, Univ. «Alex. I. Cuza » Iaşi, 2002

[30] Rusu, A. GIS tools for the evaluation of the territorial impact assessment of transportation projects funded by the European union in Romania, International Multidisciplinary Scientific GeoConference Surveying Geology and Mining Ecology Management, SGEM, 2015, 2 (2) ,pp.907, 2015

[31] Schürmann, C., Spiekermann, K., Wegener, M., Accessibility indicators: model and report. In: SASI Deliverable D5. Report to the European Commission. Institute für Raumplanung, Universität Dortmund, Dortmund, 1997.

[32] Östh, J., Reggiani, A., Galiazzo, G., Novel methods for the estimation of cost-- distance decay in potential accessibility models. In: Condeço-Melhorado, A., Reggiani, A., Gutiérrez, J. (Eds.), Accessibility and Spatial Interaction. Edward Elgar, Cheltenham, 2014

[33] Spiekermann, K., Wegener, M., Květoň, V., Marada, M., Schürmann, C., Biosca, O., Ulied Segui, A., Antikainen, H., Kotavaara, O., Rusanen, J., Bielańska, D., Fiorello, D., Komornicki, T., Rosik, P., Stępniak, M., TRACC Transport Accessibility at Regional/Local Scale and patterns in Europe. Final Report. ESPON Applied Research, pp. 1-274, 2015

[34] Muntele, I., O. Groza, G. Țucănașu, Al Rusu, and D. Tudora. "Calitatea infrastructurii de transporturi ca premisă a diferențierii spațiilor rurale din Moldova." UAIC, 2010

[35] Reggiani, A., Bucci, P., Russo, G., Accessibility and impedance forms: empirical applications to the German commuting network, International Regional Science Review, 2011, 34, https://doi.org/10.1177/0160017610387296

[36] Martínez, L.M., Viegas, J.M., A new approach to modeling distance-decay functions for accessibility assessment in transport studies, Journal of Transportation Geography, 2013, 26, https://doi.org/10.1016/j.jtrangeo.2012.08.018

[37] Eva, M., Corodescu-Roșca, E., Cehan, A., Muntele, I. Conceptualizarea și măsurarea accesibilității spațiale la serviciile de interes general. Geographia Napocensis, 2020, XIV $(1 / 2)$, pp. 1-23. (submitted to publication, under evaluation).

[38] LEGE nr.351 din 6 iulie 2001 privind aprobarea Planului de amenajare a teritoriului naţional Secţiunea a IV-a Reţeaua de localităţi, M.Of. nr. 408/24 iul. 2001

[39] Liu, S.; Zhu, X. An integrated GIS approach to accessibility analysis. Transactions in GIS, $2004,8,45-62$.

[40] Charles Raux, Aurélie Mercier et Nicolas Ovtracht, Evaluation économique des politiques de transport et indicateurs d'accessibilité spatiale : I'apport des SIG, Cybergeo : European Journal of Geography [En ligne], Systèmes, Modélisation, Géostatistiques, document 435, mis en ligne le 11 décembre 2008, URL:http://journals.openedition.org/cybergeo/21333; DOI: https://doi.org/10.4000/cybergeo. 21333

[41] Accessibilité sociale et accessibilité économique mondiales au début des années 1990, Claude Grasland, L'Information Géographique, 1999, 63-3 
[42] An adaptive inverse-distance weighting spatial interpolation technique, George Y.Lu, David W.Wong, Computers \& Geosciences, 2008, Volume 34, Issue 9, September

[43]Ioan Ianoş, Alexandru-Ionut Petrişor, Daniela Zamfir, Andreea-Loreta Cercleux, Ilinca-Valentina Stoica, Cristian Tălângă, In search of a relevant index measuring territorial disparities in a transition country. Romania as a case study, Die Erde-Journal of the Geographical Society of Berlin, 2013, Volume 144, 1

[44] J. Benedek, N. Veress, Economic Disparities and Changes in the Convergence of the Romanian NUTS 2 and NUTS 3 Regions, Romanian Review of Regional Studies, 2013, Vol. 9, Issue 1

[45] Condeço-Melhorado, M., Demirel, H., Kompil, M., Navajas, E., Christidis, P., The impact of measuring internal travel distances on self-potentials and accessibility, European Journal of Transportation Infrastructures, 2016, Res. 16 (2), 300-318. 